\title{
Monumental earthen architecture in the humid tropics of Mexico: archaeological evidence of a millenary tradition
}

\author{
A. Daneels ${ }^{1}$, L. Guerrero ${ }^{2}$ \& G. Liberotti ${ }^{3}$ \\ ${ }^{1}$ Institute of Anthropological Research, \\ National Autonomous University of Mexico, Mexico \\ ${ }^{2}$ Department of Creative Synthesis, \\ Autonomous Metropolitan University, Mexico \\ ${ }^{3}$ Independent researcher, L'Aquila, Italy
}

\begin{abstract}
Archaeological research since 2004 in the humid tropical coastal lowlands along the Gulf of Mexico has revealed that earth was successfully used as building material for monumental architecture in an extremely adverse environment of heavy summer rainfalls and winter hurricanes. At the site of La Joya, one of the many earthen sites of Central and Southern Veracruz, pyramids, palaces, and ball courts of a size equalling or surpassing contemporaneous stone constructions, were erected and modified during the first millennium AD. For the first time in Mexican research, the combined efforts of archaeologists, architects, restorers, chemists, geologists, and biologists permit understanding the techniques that made these constructions possible in the tropical environment. Our paper focuses on a new reconstruction of the building sequence of the East Palace Annex at La Joya, to emphasize the quality of the architecture and the importance of this underrated heritage. We address aspects of construction technique and architectural layout, pointing out the original strategies developed by the ancient builders

Keywords: earth construction, pre-Columbian architecture, archaeological excavations, 3D reconstruction, preservation, physical and chemical analysis, humid tropical environment, building techniques.
\end{abstract}




\section{Introduction}

We present preliminary interpretations concerning the construction and architectural components of one of the major buildings of the pre-Columbian city currently known by the name of La Joya, on the Gulf coast of Mexico. The information was obtained during a series of projects led by the first author since 1981. Systematic survey located 131 sites with earthen architecture compounds in only $1200 \mathrm{~km}^{2}$, allowing definition of La Joya as the capital of a Classic period state, spanning the first millennium AD (Daneels [2]). Since 2004, excavations at the site, funded by the National Autonomous University of Mexico, obtain information before modern-day brickworks destroy the remaining $5 \%$ of the site.

The excavations revealed a completely unexpected wealth of information on a monumental architectural tradition in raw earth. This is remarkable because, although evidence of the use of earth as a building material is commonplace in Mexico since very early times, previous research had focused only on preColumbian, Colonial and historic buildings in the semiarid and arid highlands of the country. Archaeological sites along the tropical Gulf coast were generally described as "mounds", thought to support simple wattle-and-daub thatched structures (for example see Urcid and Killion [17, Fig. 22]). Only very recently have data on architectural design and labour expenditure been reported for early Olmec period sites on the southern Gulf Coast, though technological studies are still unpublished (Cyphers [1]). The La Joya data thus represent a significant contribution to the understanding of this heretofore unknown heritage of monumental architecture that successfully used only earth, without stone, brick or lime, in a humid tropical coastal environment.

Our research has endeavoured to reproduce pre-Columbian technological know-how, but so far has failed to achieve comparable results, though many of its tenets are now understood through sedimentary, petrographical, mineralogical and chemical analysis (Daneels and Guerrero [5], Daneels et al. [6], Kita et al. [11], Liberotti and Daneels [12]) and alternatives of preservation are being tested (Guerrero and Daneels [8]). Here we present for the first time the full East Platform's Annex building sequence as obtained up to now from archaeological excavations, drawing parallels to contemporary stone masonry from contemporary Maya and highland cultures of Mexico.

\section{Location, environment, and cultural affiliation}

The La Joya site is located in the central part of the state of Veracruz, which stretches along the Gulf of Mexico. Located $6 \mathrm{~km}$ inland from the coast, at $19^{\circ} 04^{\prime} \mathrm{N}$ latitude and $96^{\circ} 09^{\prime} \mathrm{W}$ longitude, it is since 2009 part of the metropolitan urban area of the port of Veracruz, soon to be fully urbanized (fig. 1 inset). 


\section{LA JOYA, VERACRUZ, MEXICO}

Solid black areas: conserved sectors

1. Pyramid

2. North Platform

3. East Platform

4. Ball court

5. Artificial water reservoirs
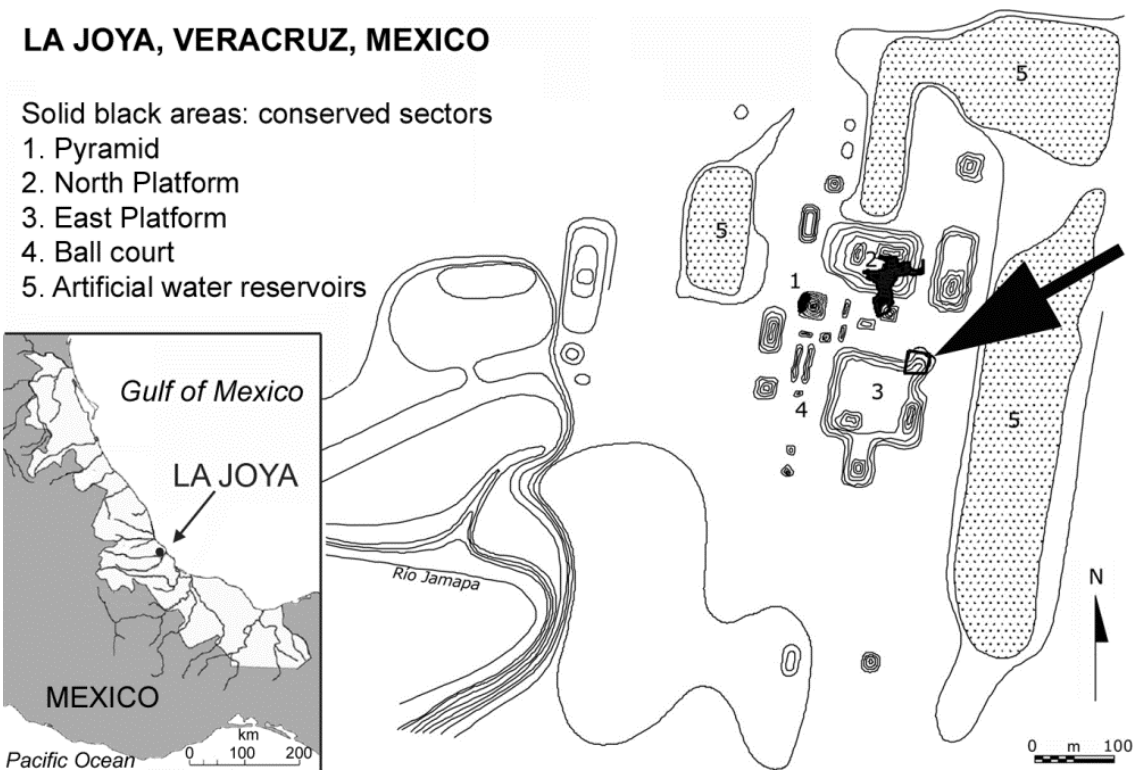

Figure 1: $\quad$ Contour map of La Joya as established by Escalona [7] and Daneels [3], with arrow pointing to east platform's extant remains. inset: location of site in the State of Veracruz (outlined in white).

The regional climatic conditions are to the modern mind totally adverse for raw earth construction: heavy monsoon rainfall averaging 1500 to $2000 \mathrm{~mm}$ per year, fall mainly in the summer months, while autumn hurricanes (4 to 5 a year) and almost weekly northerly gales during the winter bring in saline air from the large with sandblasting force. In the springtime, extreme dry conditions send temperatures up to $39^{\circ} \mathrm{C}$ in the shadow and above $70^{\circ} \mathrm{C}$ in the sunlight (Daneels et al. [6]).

La Joya and the surrounding sites belong to what is called the South-Central Veracruz culture sphere of the Classic period, heir to the Olmec culture of the Preclassic period. The settlement system reflects the existence of a series of micro-states, state level entities of very small scale (range of $100 \mathrm{~km}^{2}$ ), that spans the first millennium AD (Daneels [2]).

\section{Site layout and sequence}

The La Joya site was occupied continuously since 1600 BC, based on ceramic evidence obtained from fill material, but the monumental building activity starts by 200 BC with the North Platform palatial compound. By 200 AD, the site has a closed plaza group dominated by a 4 staircase pyramid, and surrounded by three connecting artificial reservoirs that served as borrow pits, but also as a flood protection system, architectural barrier, and reflecting pools. These reservoirs 
control visitor's viewpoints and route of access, and differentiate the monumental built compound from the regular residential areas outside the reservoirs, composed of palm thatch houses hidden amongst tree-dominated house-gardens and fields. This sent a strong visual and symbolic message to all inhabitants of the superior hierarchy of the central compound residents (fig. 1). Such water reservoirs are common in the karstic Maya area, where due to the scarcity of surface water they are associated with control by political elites of access to water (Scarborough and Lucero [15]). In the case of the Gulf alluvial plains, where perennial rivers are abundant, these reservoirs probably had a role in urban layout and ritual use (Stark [16]).

By $300 \mathrm{AD}$, the East Platform is added, showing material and stylistic evidence of commercial contact with the contemporary major Mesoamerican highland capitals of Teotihuacan and Cantona, probably based on a thriving coastal cotton production. Yet, as we will show, the architectural layouts manifest more affinity with the Maya region, where climatic conditions are similar.

Between 400 and $600 \mathrm{AD}$, the urban core of La Joya acquired its final layout consisting of two large open spaces, the first of which was over one hectare. This latter was bounded to the west by the main pyramid, to the north by two monumental platforms, and to the southeast and south by the East Platform, which will be the focus of this paper. A smaller plaza was located south of the pyramid, closed off by two lateral platforms and a $50 \mathrm{~m}$ long ballgame court to the south. This formed the layout typical of the region, called the Standard Plan (Daneels [2]). Excavations revealed that the monumental platforms were palatial compounds for the ruling classes, combining administrative, residential and ritual functions (Daneels [3, 4]). The East Platform, the object of this study, was heavily damaged by brick makers, with only its north-eastern portion remaining. The archaeological excavations up to now have identified the third and fourth building stages. During these phases, the building started as a palatial residence, transforming at the death of the last lord into a three-tiered commemorative pyramid with ritual functions (fig. 2). This paper reviews the information on the third building stage that spanned the period between 300 and 700 AD.

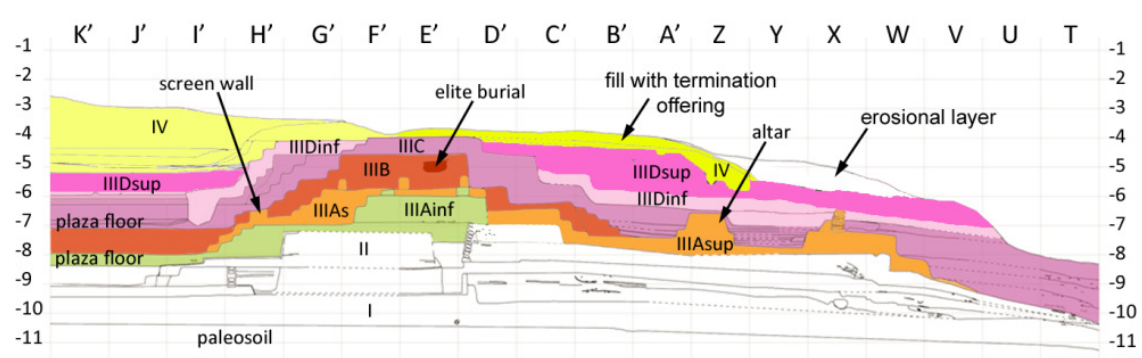

Figure 2: $\quad$ E-W profile of the east platform's NE Annex (vertical scale in meters). 


\section{The east platform}

Mesoamerican urbanism commonly displays cyclical rebuilding of architecture. For political and cultural reasons, after certain periods the societies renewed their buildings dismantling part of the existing structures and placing new buildings directly above the pre-existing ones. Often the original function remained, but sometimes it changed dramatically, as in the case of East Platform. Here, urban spaces were reused and re-semanticized over more than a thousand years of city life. Therefore, the study of these superimposed construction phases allows for a valuable reading of changes and continuities in the structures, which respond to the development and socio-political organization of the city.

The East Platform had six building stages spanning the Middle and Late Classic period (300-1000 AD) (fig. 2). However, the two oldest phases have not been explored yet, and the last two stages only occurred on the platform's main body, now completely destroyed by modern brickworks. But the third and fourth stages already studied on the NE annex are very interesting since they demonstrate three distinct functions. The main building had first a residential function (stage IIIA), which lasted to the end of the sixth century. Later it was covered and turned into a ritual space that remained for about 150-200 years (stage IIIB-D) (fig. 3). Finally the compound was intentionally covered over to obliterate all evidence of the previous building, the bunker-like mass remaining as an anonymous structure closing the southeast corner of the main plaza, till the abandonment of the city around AD 1000 (Stage IV).

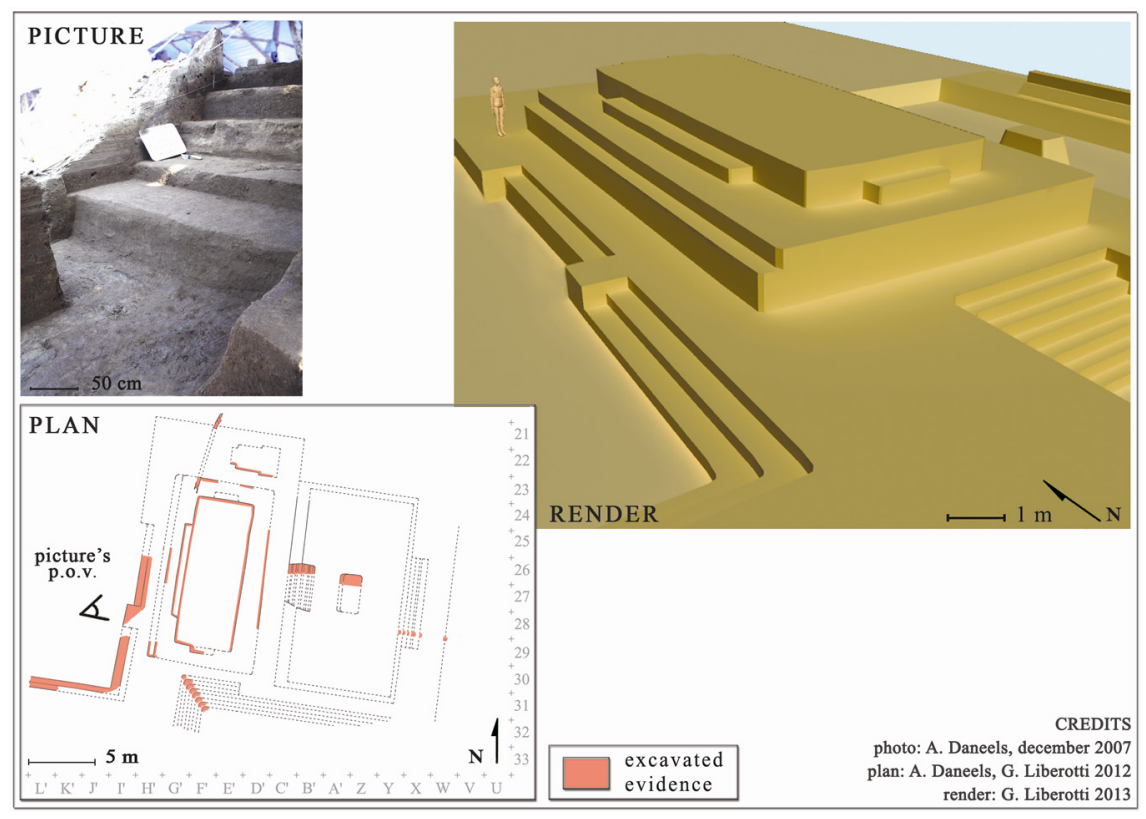

Figure 3: $\quad$ Stage IIIB commemorative pyramid. 
The size of the living spaces, similar to that of the Maya area (Inomata et al. [10]), the urban relationships of the compound, and the archaeological materials found during excavations, show that the residence could be considered a palace, where several elite generations lived and performed ritual and administrative activities (Daneels [4]). Both were intentionally dismantled and burned for ritual purpose. During this process, ceramic vessels, figurines, and human victims were offered, demonstrating the importance of the occupants who had lived there. Such consecratory rites are common in Mesoamerica (Mock [14]). These destructive processes preserved the remains of walls as well as the charred offering materials, providing details of the building system as well as invaluable information on the dimensions of the spaces, roofing, and everyday activities, and allowing C14 dating.

\section{Internal layout and room functions}

The first palace (dubbed IIIA inferior in the excavation sequence) was destroyed about $480 \mathrm{AD}$, while the second (IIIA superior) was burned shortly after, about $500 \mathrm{AD}$ (Daneels [3]). There was no real difference in layout between the two superposed buildings, only in size. The oldest one was $11.9 \mathrm{~m}$ long and $5.6 \mathrm{~m}$ wide (fig. 4), while the new residence measured 11.3 by $4.6 \mathrm{~m}$; the one meter decrease in the building width forced narrower rooms. Both buildings were built on a $90 \mathrm{~cm}$ high basal platform, and the access was through a front stairway. The buildings and staircase stood on a platform accessible only from the main square on the west by a staircase aligned to the axis of the façade.

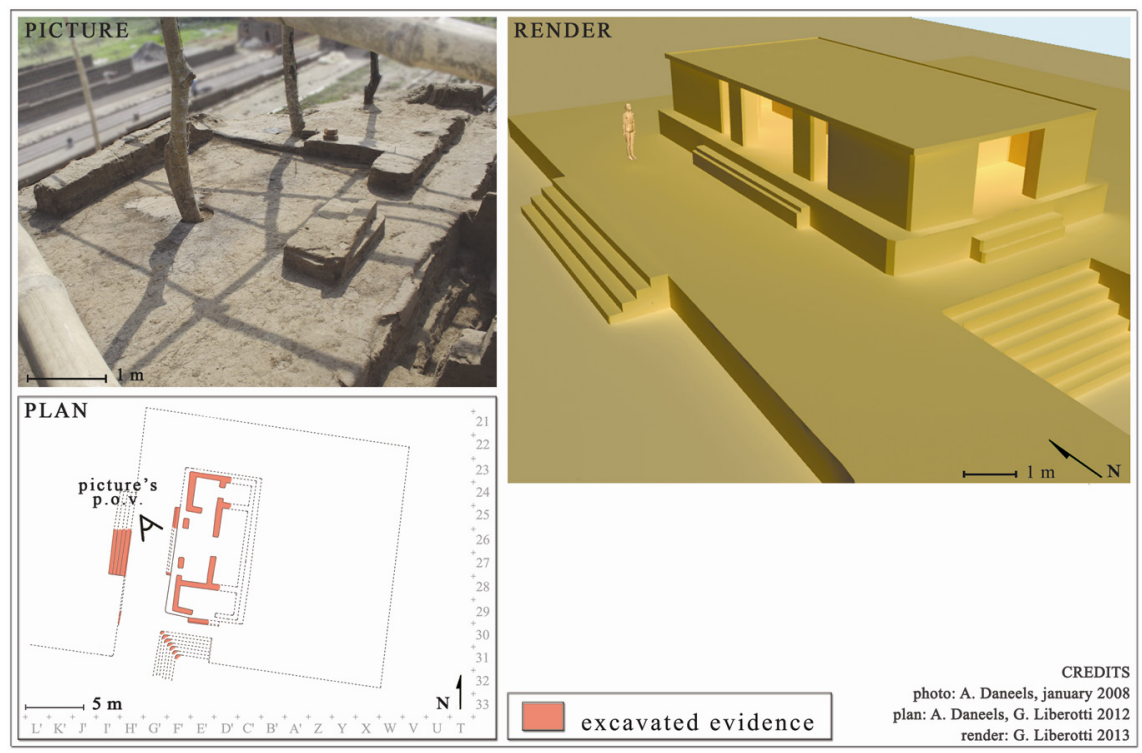

Figure 4: $\quad$ First residential building (stage IIIA inferior). 
The first palace was placed to the back of this raised platform, thereby leaving a wide terrace that gave some kind of privacy to the whole compound, being out of the view of the people who walked along the main plaza. When the second palace was built, it was moved forward almost flush with the top of the plaza staircase, which may have led to the ad hoc building of a screen wall to regain privacy (figs. 2 and 5). Behind the main building was a sunken patio about $9 \mathrm{x}$ $16 \mathrm{~m}$ large with a central altar, access to which was controlled by corridors and stairways. Such altars for private cult are common both in highland and Maya palace architecture.

Both building stages were elongated rectangles oriented north-south, as in many other pre-Hispanic sites and contemporary vernacular architecture. This orientation responded to bioclimatic conditions, as the short sides reduced exposure to the dominant north winds and direct sunlight to the south, hence providing good thermal conditions. The front entrance portico, which gave access to the compound, opened to the main plaza to the west, to allow ventilation of the indoor spaces. This provided a visual control of the city from a shaded space, whose earthen floors, walls and ceilings likely kept the temperature in acceptable comfort ranges, a prime necessity in a climate as hot and humid as that of La Joya. The front portico repeats one of the most common layouts in Mesoamerican and more particularly Maya residential architecture (Inomata et al. [10]). This consists of a symmetrical pattern in which the front is divided into three parts: a central doorway and two smooth walls on either side. The latter are approximately half the size of the central doorway, which in turn is subdivided into three sections by a pair of columns. In this way the axis of the façade is hierarchically arranged emphasizing the central room, the main access to the house. This access led to the main daytime living space: the portico or entrance hall. It is a transition area between open space and the main central room to the back, and where the royal personalities performed administrative and ritual activities. Besides its connective function, it served as a source of natural light and ventilation.

To the north of the portico, a doorway gave access to two interconnected rooms. The northwestern one provided the unique discovery of a large amount of charred corn cobs (Daneels [3]). This is the first evidence of food storage in Gulf coast sites, and it is of great socioeconomic interest since it was located in the house of prominent people. Moreover, since these northern rooms never received direct sunlight and their walls were cooled by the dominant winds, a better conservation of corn was achieved, taking advantage of the local bioclimatic conditions. The southern rooms had no direct communication with the portico. A separate door, with its own staircase, allowed descent to the terrace. A fire pit full of charcoal on the floor of the second building stage, along with some bird bones and blowgun pellets, suggests that this place served as the kitchen of the house. Their southern location allowed the northern winds to draw the smoke outside.

The second building stage revealed an interesting feature: an off-axis, $45 \mathrm{~cm}$ wide opening in the back wall (fig. 5). In most pre-Hispanic architecture, the concept of a "window", such as developed in other parts of the world as we 
understand it today, does not exist. Roofed spaces only had a door to control access of people, air, and light. However, we found an interesting ventilation system in the second residence of the East Platform. Given the hygrothermal conditions of the humid tropics, it was necessary to induce airflow through convection and cross ventilation. Therefore, the small vents in the lower parts of the walls enabled outside air to enter through the upward shift of the inside warm air. This remarkable feature, which is currently used in bioclimatic architecture, was also identified in the Maya area, sharing with La Joya the high temperature and humidity typical of the tropical lowlands (Valdés [18, p. 22]).

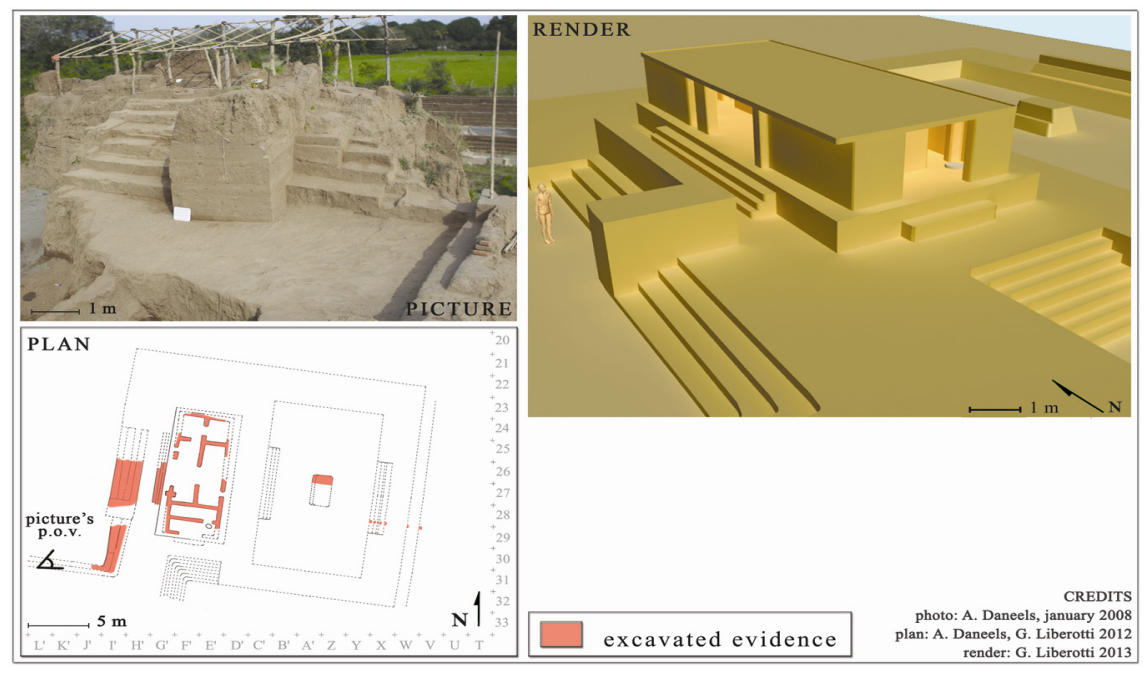

Figure 5: $\quad$ Second residential building (stage IIIA superior).

The residential layout of both building stages is paralleled in two other contemporaneous palatial buildings within the same region, showing it is a recurrent Classic period pattern (Daneels [4]). A very similar layout was recently reported also from the Maya area (Inomata et al. [10]), where Aguateca's Late Classic palace group, $10,000 \mathrm{~m}^{2}$ in all, has a principal residence (M7-32) with similar internal room space, room functions, and even parallel termination rites with partial dismantlement and elite artefacts intentionally broken and strewn across the floor. The absolute size of this palace was larger (15x8m), but this is principally due to the $1 \mathrm{~m}$ wide limestone walls needed to support the vaulted masonry roof.

In the case of the La Joya example, it is necessary to take into account that this palace is the main building of the small NE annex of about $610 \mathrm{~m}^{2}$, actually only a very small part of the main body of the East Platform, which spanned an additional $15,100 \mathrm{~m}^{2}$ and which had other buildings on top (fig. 1). This is a reminder of the monumentality of this Gulf Coast earthen architecture, until now largely ignored in Mesoamerican research. 


\section{Materials and building systems}

Although the use of water reservoirs, residence orientation, ventilation systems, and room distribution and function, show close parallels to Maya elite architecture, while other characteristics are generally Mesoamerican (acropolislike palace compounds on huge raised platforms, sequential superimposed building sequences, consecration offerings, private courts with altars), the building systems are original, developed to use earth mixes composed mainly of expansive clays.

The basal platforms were made with fills of soil removed from its natural geologic matrix, which was compacted and modelled. Sometimes, layers of pottery shards covered the surface of the fill layers, likely facilitating the process of compaction and screeding. Contrary to the case of the second stage of the Pyramid and the North Platform, in the East Platform we found no evidence of the use of fill blocks of contrasting composition, alternating clay and sandy loam (Daneels and Guerrero [5]). This technique, effective to control the internal pressure of a massive fill and to enhance the rapid filtration of water, was probably not required in the case of the third and fourth building stages of the East Platform, where the partly dismantled walls and drainage systems of the substructures provided the structural buttress for the new buildings. The fills are covered by a uniform capping layer 5 to $7 \mathrm{~cm}$ thick, consisting of a mixture of finely sieved silt with a high proportion of clay and a small fraction of crushed pottery shards, which gave the final shape to the platform, levelling the surface till getting the slope required for rain to run off from floors and near vertical revetments.

Walls, columns and pilasters were built using large adobe blocks with surprisingly constant dimensions: $80 \mathrm{~cm}$ long, $40 \mathrm{~cm}$ wide and $10 \mathrm{~cm}$ thick. These dimensions demonstrate a strong understanding of structural rules because such a geometric relationship provides linear overlaps, and perfectly interlocked corners, giving continuity to the structural strength (Daneels and Guerrero [5], Guerrero et al. [9]). Even if the composition of the adobes varies, they are generally made with clay, thus requiring the addition of chopped grass to avoid cracking during drying. The height of the walls was at least $1.75 \mathrm{~m}$.; although there is no complete wall remaining, a section of facing that collapsed on the floor showed the original height.

Another key to the success of earthen architecture in such adverse weather conditions seems to lie in the coating, which was applied directly on the adobes, floors, steps, and revetments without interruption. There is no evidence of any joints in these facing layers. Another unexpected discovery was that the coatings of two hundred years old structures (as dated by radiocarbon and ceramic association) were renewed only four times. This means that each of them lasted about fifty years, despite the humid tropical climate (Daneels and Guerrero [5]). At the moment, a crucial part of our research is focusing on the identification of the coating's compositional elements, because if we could reproduce the coating, we could use it to preserve the site and aid contemporary architecture. 
Daneels and Guerrero [5] report the results of X-ray fluorescence (XRF), diffraction (XRD) and FTIR spectroscopy (Fourier Transform InfraRed), performed on facing and adobe samples. These results confirm the presence of organic components, whose nature has not yet been clearly defined. Recent results of Nuclear Magnetic Resonance (NMR) and thin-layer chromatography (TLC) show compounds with bituminous characteristics as well as organic residues that may act as emulsifiers (Kita et al. [11]). Likely the polymerization of the hydrocarbon consolidates the soil, protects it from water erosion and also serves to control the growth of parasitic plants and animals, of which no evidence was found on pre-Columbian surfaces during the excavation. Petroleum seeps naturally occur along the Mexican Gulf coast, and its pre-Columbian use is attested as paint on ceramic vessels and figurines, as caulk on canoes, and occasionally as floor covering (Cyphers [1], Wendt and Cyphers [19]).

Another fact that stands out is that the rooms were covered with flat roofs, as evidence seems to indicate (Daneels and Guerrero [5]). The structure resembles wattle and daub walls, but it is applied horizontally as a flat roof anchored to the top of the adobe walls, probably with a slight incline, surrounded by parapets to evacuate the rainwater towards an as yet unidentified roof drainage system (gargoyles?). Although beam-and-mortar roofs are common both in highland and Maya area sites, these are characterized by stucco facing. The La Joya evidence of flat raw earthen roofs is therefore surprising, in view of the high rainfall regime of the Gulf Coast.

Once captured at floor level, the water was evacuated through a sophisticated subfloor drainage system using a standardized module of pipe made of thick and slightly conical terracotta, described previously (Daneels et al. [6, p. 65]). Identical drainage tubes have been reported from Middle to Late Classic earthen architecture sites on the Pacific coast of Guatemala (Medrano and Bove [13]).

\section{Conclusions}

Studies on the conservation of the earthen architectural heritage in Mexico are relatively recent and still in an experimental stage. The investigations concerning earthen structures in humid tropical areas are even scarcer. Though the data on social organization and daily life of La Joya inhabitants are still being analyzed, it is clear that this civilization was able to achieve a remarkable technological know-how in terms of monumental earthen architecture in adverse weather conditions. Unravelling the technology could open the way towards understanding this ancient pre-Columbian architecture and possibly reintroducing this sustainable building system in the Mexican tropics.

The parallels to Mesoamerican architecture in general demonstrate that this Gulf architecture achieved the same degree of sophistication and monumentality, even though built of earth and not stone, while specific similarities to Maya architecture in particular seem to reflect common responses to humid tropical environmental conditions. It is very important that knowledge about this ignored heritage should be advanced and shared, so that its preservation becomes a priority. 


\section{Acknowledgements}

This study is part of A. Daneels' project funded by grants of the National Autonomous University of Mexico (UNAM) Program for the Advancement of Research and Technological Innovation Projects (PAPIIT) of the General Direction of Academic Personnel Affairs (DGAPA) IN305503 (2004-2006), IN405009 (2009-2011) and IN300812 (2012-2014), as well as funding by the National Council for Science and Technology (CONACyT Fondo Institucional 90636), FAMSI (Grant 07021) and Dumbarton Oaks (2007-2008); permissions to excavate at the La Joya site and to analyze pre-Columbian construction samples from the site were granted by the Archaeology Council of Mexico's National Institute for Anthropology and History (INAH). G. Liberotti's participation was funded by a doctoral grant from the Ministry of Foreign Affairs and a postdoctoral grant from the Sapienza University of Rome.

\section{References}

[1] Cyphers, A., Arquitectura. Las bellas teorías y los terribles hechos. Controversias sobre los olmecas del Preclásico inferior, by A. Cyphers, Institute of Anthropological Research, National Autonomous University of Mexico: Mexico City, pp. 43-76, 2012.

[2] Daneels, A., Ballcourts and Politics in the Lower Cotaxtla Valley: A Model to Understand Classic Central Veracruz. Classic-Period Cultural Currents in Southern and Central Veracruz, ed. Ph. J. Arnold III and Ch. A. Pool, Dumbarton Oaks Research Library and Collections, Harvard University Press: Washington, D.C., pp. 197-223, 2008.

[3] Daneels, A., Monumental Earthen Architecture at La Joya, Veracruz, Mexico. Final Report. Foundation for the Advancement of Mesoamerican Studies, Crystal River (FL), Online. www.famsi.org/reports/07021, 2008.

[4] Daneels, A., Organización interna de residencias de elite del periodo Clásico en el Centro de Veracruz. VII Coloquio Pedro Bosch Gimpera, ed. G. Acosta, Institute of Anthropological Research, National Autonomous University of Mexico: Mexico City, pp. 155-169, 2012.

[5] Daneels, A. and Guerrero L., Millenary Earthen Architecture in the Tropical Lowlands of Mexico. APT Bulletin 42 (1), pp. 11-18, 2011.

[6] Daneels, A., Guerrero L. and Roux R., Caracterización de los materiales y sistemas constructivos de tierra en la ciudad prehispánica de La Joya, Veracruz, México. Terra em Seminário. IX SIACOT, eds. M. Fernandes, M. Correia and F. Jorge, Argumentum: Lisboa, pp. 64-68, 2010.

[7] Escalona, A., Ruinas de "El Tejar". Informe rendido a Luis Rosado Vega, Director Jefe de la Expedición Científica Mexicana, acerca de diversos trabajos de exploración en las Ruinas arqueológicas de El Tejar, Ver. Technical Archive of the Coordination of Archaeology, National Institute of Anthropology and History, Tome CXIX. Vol. II: Mexico City, 1937.

[8] Guerrero, L. and Daneels A., La construction en terre crue dans les tropiques humides: un cas archéologique exceptionnel au Véracruz, 
Mexique. XXVII Assemblée Générale de l'ICOMOS 2011, ICOMOS: Paris, p. 422-430, 2012. Online http://icomos.org/en/component/content/article? id=477:icomos-17th-general-assembly-scientific-symposium-proceedings

[9] Guerrero, L.; Meraz L. and Soria F. J., Cualidades sismorresistentes de las viviendas de adobe en las faldas del volcán Popocatépetl. Patrimonio construido con tierra, ed. L. Guerrero, Universidad Autónoma Metropolitana - Xochimilco: México City, pp. 91-107, 2007.

[10] Inomata, T., Triadan D., Ponciano E., Terry R. and Beaubien H.F., In the Palace of the Fallen King: The Royal Residential Complex at Aguateca, Guatemala. Journal of Field Archaeology 28 (3-4), pp. 287-306, 2001.

[11] Kita, Y., Daneels A. and Romo de Vivar A., Chemical analysis to identify organic compounds in pre-Columbian monumental earthen architecture. The Online Journal of Science and Technology 3 (1), pp. 39-45, 2013.

[12] Liberotti, G. and Daneels A., Técnicas constructivas en tierra: reconstrucción 3D y análisis químico-físicos en los sitios de La Joya (México) y Arslantepe (Turquía). Boletín de la Sociedad Geológica Mexicana 64 (1), pp. 79-89, 2012.

[13] Medrano, S. and Bove F., Construcciones de tierra en Escuintla, La arquitectura de tierra mesoamericana, ed. A. Daneels, Institute of Anthropological Research, National Autonomous University of Mexico: Mexico City, in press.

[14] Mock, S. B., ed. The Sowing and the Dawning: Termination, Dedication, and Transformation in the Archaeological and Ethnographic Record of Mesoamerica, University of New Mexico Press: Albuquerque, 1998.

[15] Scarborough, V.L. and Lucero L., The Non-Hierarchical Development of Complexity in the Semitropics: Water and Cooperation. Water History 2(2), pp.185-205, 2011.

[16] Stark, B. L., Discusión de Dos Aspectos del Patrón de Asentamiento en La Mixtequilla. Memoria del Coloquio Arqueológico del Centro y Sur de Veracruz, eds. S. Ladrón de Guevara and S. Vásquez, Universidad Veracruzana: Jalapa, pp. 211-222, 1997.

[17] Urcid, J. and Killion Th., Social Landscapes and Political Dynamics in the Southern Gulf-Coast Lowlands (AD 500-1000). Classic-Period Cultural Currents in Southern and Central Veracruz, eds. Ph. J. Arnold III and Ch. A. Pool, Dumbarton Oaks Research Library and Collections, Harvard University Press: Washington, D.C., pp. 259-291, 2008.

[18] Valdés, J. A., El crecimiento de la civilización maya en el área central durante el preclásico tardío: una vista desde el Grupo $\mathrm{H}$ de Uaxactún. Utz'ib 1(2), pp. 16-31, 1992.

[19] Wendt, C. J. and Cyphers A. How the Olmec Used Bitumen in Ancient Mesoamerica, Journal of Anthropological Archaeology 27(2), pp. 175-191, 2008. 